\title{
Livros para infâncias diversas: onze casos de editoras independentes da Argentina e do Brasil
}

\author{
Books for Diverse Children: \\ eleven cases of Independent Publishers in Argentina and Brazil \\ Libros para infancias diversas: \\ once casos de editoriales independientes de Argentina y de Brasil \\ Ivana Mihal \\ Daniela Szpilbarg* \\ Ana Elisa Ribeiro**
}

\section{Resumo}

Neste artigo, com base em uma noção expandida, e aqui ensaiada, de bibliodiversidade, que considera o tema da diversidade sexual, de gênero e as infâncias diversas, analisamos brevemente os projetos de seis editoras independentes argentinas e cinco brasileiras. Estas casas editoriais publicaram obras sobre temáticas ligadas à diversidade, em especial infâncias trans e questões de gênero, dirigidas ao público infantil, decorridos os anos 2000. Com base na análise dos sites e de seus breves catálogos (que ainda se constroem), concluímos que as editoras independentes têm caminhado pari passu com mudanças e conquistas sociais importantes em relação ao direito à diversidade, como demonstram livros aqui tomados como exemplos.

Palavras-chave: editora independente, diversidade, infâncias, bibliodiversidade.

\section{Abstract}

In this article, based on an expanded and tentative concept of bibliodiversity that considers the subjects of sexual diversity, gender and diverse children, we briefly analyze the projects of six Argentine and five Brazilian independent publishing houses. In the 2000s, these publishers edited books about diversity, especially about transgender children and gender questions, directed towards children. Based in a brief analysis of the sites and catalogues (still in development), we conclude that the independent publishing houses have accompanied important changes and social achievements related to diversity rights, as demonstrated by the books shown here as examples.

Keywords: independent publishing house, diversity, childhood, bibliodiversity.

\begin{abstract}
Resumen
En este artículo, con base en una noción expandida y ensayada aquí, de bibliodiversidad, que considera el tema de la diversidad sexual, de género y las infancias diversas, analizamos brevemente los proyectos de seis editoriales independientes argentinas y cinco brasileñas. Estas casas editoriales publicaron obras sobre temáticas ligadas a la diversidad, especialmente infancias trans $y$ cuestiones de género, dirigidas al público infantil desde los años 2000. Con base en un análisis de sitios web y de sus catálogos - que están todavía en construcción - concluimos que las editoriales independientes han ido acompañando los cambios y conquistas sociales importantes en relación con el derecho a la diversidad, como demuestran los libros aquí tomados como ejemplos.
\end{abstract}

Palabras-clave: editoriales independentes, diversidad, infancias, bibliodiversidad.

\footnotetext{
" Universidad Nacional de San Martín (UNSAM), Ciudad Autónoma de Buenos Aires, Argentina. (Dorcid.org/0000-0002-23148003. E-mail: ivana.mihal@gmail.com

** Universidad de Buenos Aires (UBA), Ciudad Autónoma de Buenos Aires, Argentina. (Dorcid.org/0000-0003-1310-4514. E-mail: danielaszpilbarg@gmail.com

**** Centro Federal de Educação Tecnológica de Minas Gerais (Cefet-MG), Belo Horizonte, Minas Gerais, Brasil. (Dorcid.org/00000002-4422-7480. E-mail: anadigital@gmail.com
} 


\section{Breve contextualização: diversidade e sociedade}

Nos últimos anos, a publicação de autores e obras relacionados a gêneros e feminismos vem aumentando, de mãos dadas com a crescente visibilidade de lutas de diferentes movimentos sociais - feministas, dissidentes etc. - que contestam maneiras convencionais de se entender o mundo. Diferentes identidades e gêneros não construídos sob o binômio feminino/masculino já vinham desafiando uma ordem heteronormativa e hegemônica, o que se tornou muito mais relevante com a $8 \mathrm{M}$ (Greve Internacional da Mulher) em diferentes países. Incluem-se nesse debate considerações sobre feminicídios e transfeminicidas ou transvesticidas, bem como a discussão sobre a descriminalização do aborto e a legalização da interrupção gratuita e segura da gravidez - todas pautas e demandas por direitos que foram adicionadas às queixas preexistentes sobre desigualdades de gênero.

Antes de tratar das infâncias diversas, tanto na Argentina quanto no Brasil, houve uma sorte de questões precedentes: na Argentina, por exemplo, em 2006, foi aprovada a Lei n. 26.150, que visa garantir que todas as crianças e adolescentes tenham direito de receber educação sexual abrangente, em estabelecimentos de ensino públicos e privados. Em 2010, foi promulgada a Lei n. 26.618 sobre o casamento civil, conhecida como Lei do Casamento Igual, que estabelece os mesmos requisitos e efeitos, independentemente de os cônjuges serem do mesmo sexo ou não. Em 2012, foi promulgada a Lei n. 26.743 sobre identidade de gênero, que concede a todos/as o direito ao reconhecimento de sua identidade, a seu livre desenvolvimento e a serem tratados/as de acordo com sua identidade de gênero. Nesse mesmo ano, a Câmara dos Deputados da Nação aprovou, por unanimidade, a incorporação da figura do feminicídio ao Código Penal como um tipo de homicídio agravado.

No Brasil, também houve uma série de conquistas de direitos: o "casamento gay" foi declarado legal pelo Supremo Tribunal Federal em 2011 e, em 2013, o Conselho Nacional de Justiça publicou uma decisão que permitiu aos cartórios registrar a união homoafetiva. Não é uma lei, mas é um direito, que reconhece a união desses casais, com efeitos práticos importantes. Em relação ao feminicídio, em 2015 houve uma mudança no Código Penal brasileiro segundo a qual esse delito passou a ser considerado crime de ódio contra as mulheres. Muito mais timidamente do que na Argentina, no Brasil, a Base Nacional Comum Curricular (BNCC), homologada em 2017, definiu o conteúdo do ensino para todas as séries básicas, defendendo a diversidade cultural e de identidade. Não há menção à identidade de gênero, mas abre-se um espaço para o respeito à diversidade na formação dos/as cidadãos/ãs.

A despeito desse contexto positivo, as questões abordadas por editores de qualquer tipo nem sempre abrangem a diversidade expressa nas demandas dos movimentos citados. É comum observar, em diferentes mídias, notícias sobre o crescimento da publicação de títulos sobre questões de gênero e feminismos. Acima de tudo, apela-se à visibilidade das mulheres, em diferentes atividades ou áreas da esfera social. O mesmo não acontece com as questões, geralmente perturbadoras ou desconfortáveis, como a das infâncias diversas ou trans. Se a diversidade cultural fosse de fato garantida, a intervenção dos poderes públicos, por meio de políticas orientadas para o setor de livros (Galliand, 2019), não seria necessária.

Embora, na Argentina, o Estado tenha reconhecido o direito à identidade trans e concedido documento de identidade à primeira criança trans em 2013, um dos livros sobre essa experiência - Mariposas libres: derecho a vivir una infancia trans, de Gabriela Mansilla, publicado pela Editora da Universidade Nacional do General Sarmiento (Ediciones UNGS) ${ }^{1}$ - foi censurado em uma feira de livros, em dezembro de 2018 (Mihal, 2019). No Brasil, também houve episódios recentes de censura a livros de temas LGBTQ+, tais como o envio de fiscais e o recolhimento (malfadado) de livros pela prefeitura do Rio de Janeiro, durante a Bienal na cidade, em setembro de 2019. Houve forte reação de autores e editoras, que terminaram por, ao menos momentaneamente, vencer a disputa contra o conservadorismo.

\footnotetext{
${ }^{1}$ Este foi o primeiro livro editado pelas Ediciones UNGS. A autora é a mãe da Luana, nome da menina trans. O processo de incorporação desse livro e de outros que formam a coleção Intervenções, no catálogo, foi tratado em Mihal (2019).
} 
Para o caso da literatura LGBT+, na Espanha, Perriam (2012) sustenta que houve gradual configuração de um espaço, ainda que reduzido, para romances, que foram produzidos e lidos pela classe média; posteriormente, devido a pressões sociais, tais obras começaram a ter maior alcance, chegando às vitrines das livrarias, às resenhas na imprensa, na internet e ganhando leitores por meio do "boca a boca". Bittner (2019), ${ }^{2}$ em relação à literatura para jovens adultos (young adult) e às questões LGBT+, argumenta que elas não são mais focadas apenas em personagens gays ou lésbicas e vêm incluindo outras identidades de gênero e orientações sexuais. No entanto, muitos desses livros se concentram em certos grupos sociais, na população negra ou com necessidades especiais, sendo os povos indígenas praticamente excluídos dessas narrativas. De tal maneira que, mesmo em produções voltadas para a diversidade, é possível detectar sobreposições ou omissões.

Pode-se afirmar que a infância trans ainda é pouco explorada, mesmo em outros tipos de produções culturais (cinema, televisão, teatro etc.), analogamente ao desenvolvimento da produção editorial. No entanto, desde 2018, a Feira Internacional do Livro de Buenos Aires (Filba) organiza um estande chamado "Orgulho e Preconceito"; a Feira do Livro de Feministas e Diverso (Filfem) também apresenta livros destinados à infância e à literatura infantil e juvenil; há o Festival de Arte Queer, organizado pela Asociación Civil Brandon; além da Feria internacional del Libro de la Diversidade (Fildi) e do Festival de la Niñez Abrazada (Fenia), de Editores Independentes na Argentina, entre outras iniciativas. No Brasil, mesmo não havendo, segundo sabemos, uma feira específica sobre o tema, há editoras dedicadas a ele, como a Rico, no Rio de Janeiro, e coleções e obras LGBT+, até mesmo em casas editoriais grandes, que se dedicam a esse tipo de publicação, expondo-as nos eventos livreiros pelo país (bienais, feiras independentes e salões). ${ }^{3}$ Neste trabalho, propomos uma breve análise desta questão: como o Brasil e a Argentina abordam o tema das infâncias diversas na produção das editoras independentes?

\section{Bibliodiversidade e edição independente}

A maior atenção à diversidade cultural, originada nos "movimentos do terceiro mundo" nos anos 1990, encontrou sua "faceta editorial" na noção de bibliodiversidade, mas não sem polêmicas e problematizações, como argumenta Sophie Nöel ([2012]2018, p. 123-114): “os significados relacionados ao conceito de diversidade são tão múltiplos quanto subjetivos, pois contêm muitas dimensões, como a variedade de títulos realmente publicados em um determinado momento, mas também o equilíbrio".

Nöel, no entanto, omite que a diversidade cultural é característica humana, como afirmou o antropólogo francês Claude Lévi-Strauss na conferência intitulada "Raça e história", proferida para a Unesco. Foi por isso que a Declaração Universal (2001) e a Convenção sobre a Proteção e Promoção da Diversidade das Expressões Culturais (2005), no âmbito dos direitos humanos, assumiram a diversidade cultural de diferentes sociedades, minorias e etnias, além de enfatizarem a necessidade de reconhecimento e defesa - contra a homogeneização das diferenças - e desigualdades - de bens e serviços culturais relacionados à construção de imaginários, ideias e concepções (Bayardo, 2008).

A noção de bibliodiversidade ocorre transversalmente neste nosso trabalho e será objeto, oportunamente, de tentativas de reformulação teórica. Essa noção transpõe o conceito de

\footnotetext{
${ }^{2} \mathrm{O}$ autor faz uma revisão crítica do livro Representing the Rainbow in Young Adult Literature: LGBTQ+ Content since 1969, de Jenkins e Cart (2018).

${ }^{3}$ Há várias teorias ligadas à formação e à história da sigla inicial LGBT, permanecendo a linguagem como registro de como se formularam as demandas e reivindicações do ativismo pela diversidade sexual (Deangeli, 2018). A sigla, afinal, coincide com as demandas do movimento e dos ativismos pelas minorias e pela diversidade sexual. Essa sigla surgiu na década de 1990 para se referir a lésbicas, gays, bissexuais e transgênero. Ainda que agrupe as pessoas com orientações sexuais e identidades ligadas a tais palavras, o termo foi evoluindo com o tempo e a ele foram se agregando letras que buscavam incluir outras comunidades, como intersexo e queer. Por isso, a sigla se ampliou para LGBTI ou LGTBQ. O surgimento do duplo T em LGBTT corresponde, finalmente, ao fato de que as comunidades transexuais e transgênero não consideravam boa sua fusão em uma só letra "T", daí a utilização do "+" na sigla, tornando-a LGBT+. Neste artigo, consideramos a última formulação, mas, em algumas passagens, respeitamos o modo como distintas editoras se autorreferem.
} 
biodiversidade (diversidade das espécies em um meio determinado) para o mundo do livro. No entanto, de nossa perspectiva, é importante destacar que, neste trabalho, bibliodiversidade não toca apenas a diversidade cultural dos livros, mas também a presença de diferentes objetos, eventos culturais, formas de leitura e materiais editoriais que possibilitam a amplitude e a diversidade de imaginários. Dito de outro modo, a noção torna-se indispensável para se pensar a efetividade de direitos culturais e sociais.

A perspectiva comparativista adotada neste trabalho é fundamental. Deve-se considerar que trabalharemos sobre agentes do setor da edição independente, em distintos países. Há que se considerar também, retomando um trabalho fundamental de Bustamante e Symmes (2013) sobre a relação entre bibliodiversidade e edição independente, que, no plano internacional, as ideias se movem dentro de espaços de possibilidade de distintos agentes a nível nacional, e que a bibliodiversidade, derivada do princípio de diversidade cultural, emerge no terreno da produção editorial independente a partir dos vínculos entre agentes e estruturas de ordens distintas (organismos internacionais, Estados e associações de profissionais da cultura).

Este princípio de diversidade, segundo Bustamante e Symmes (2013), que estudam o caso chileno, acumula um capital simbólico, tomado e reinvestido por um setor do mundo cultural mas que permite pensar uma analogia para os casos argentino e brasileiro - para fortalecer a causa da diversidade cultural que responde a dinâmicas que não podem ser entendidas senão à luz de uma homologia de posições entre agentes diferentes, situados em distintas escalas, de onde é possível ver os modos como os organismos supranacionais, os estados nacionais e os agentes do mundo da cultura confluem, possibilitando a emergência de produções editoriais que coincidem com normativas e legislações nacionais e supranacionais, como leis de outorga de direitos a minorias sexuais, como as mencionadas no início deste texto, ou normativas específicas do uso da linguagem inclusiva, na atualidade. Nesse sentido, "a bibliodiversidade se vincula aos temas, às edições, aos autores, mas, além disso, envolve as possibilidades de construir imaginários, idiossincrasias, visões de mundo, criações, ideias, sentidos simbólicos individuais e coletivos, e experiências que definem a variedade humana" (Mihal, 2013, p. 132, tradução nossa).

É possível pensar em distintos níveis de construção da bibliodiversidade. Por um lado, a proposta das editoras sobre a variedade e a possibilidade de incluir em seus catálogos autores locais, novos e traduções (Colleu, 2008). Outro nível daria conta das diversidades linguísticas e físicas. A uniformização da língua, por exemplo, com as traduções que restringem as possibilidades de obter e decidir sobre a escolha de livros (e outros materiais de leitura) associadas a modismos, estilos e expressões próprias têm encontrado nas editoras independentes um dos meios de publicação. Embora seja possível que os editores sejam reducionistas - por exemplo, quando não levam em conta tipografias diferenciadas para livros para adultos, o que facilitaria a leitura de pessoas com dificuldades visuais, às vezes com relação ao que eles conceberam como bibliodiversidade (Mihal, 2013), a verdade é que, nos últimos anos, editores independentes (entre outros, como os universitários, na Argentina) estão expandindo suas questões e seus autores, até mesmo aderindo ao uso de uma linguagem inclusiva (Ribeiro, 2020; Mihal, 2019; Szpilbarg, 2018), a fim de abordar a diversidade humana e cultural em seus catálogos.

Em termos gerais, embora seja complexo propor uma definição unívoca de "independência editorial" ou uma definição que permita uma unificação de editoras independentes como "coletivo", quando falamos de editores independentes referimo-nos a uma espécie de "zona", na qual são pressupostos projetos editoriais de escala pequena ou média, de capital nacional, os quais dão ênfase ao cuidado com os catálogos e às propostas editoriais em muitos casos inovadoras, do estético ao temático (Szpilbarg, 2019). ${ }^{4}$ As editoras independentes, não obstante, podem e devem ser analisadas a partir de uma gama de variáveis, entre as quais, no nível metodológico, os pesquisadores deveriam incluir, por exemplo, a variável da "política de

\footnotetext{
${ }^{4}$ A categoria da independência pode ser caracterizada ou analisada a partir de distintos indicadores e variáveis, alguns dos quais têm sido, em diferentes análises: o tamanho da editora - quantidade de empregados, integrantes; faturamento; a nacionalidade do projeto; a proposta estética; o organograma (postos de trabalho); os circuitos de comercialização; as instâncias de agrupamento; a presença em feiras de livros; a inscrição dos livros com registro de ISBN; entre outras variáveis que servem para caracterizar empreendimentos editoriais.
} 
linguagem" como categoria fundamental a ser introduzida em uma análise. Neste artigo, consideramos editores independentes os que podem ser tidos como bibliodiversos, a partir de um recorte específico: livros publicados sobre a infância trans. Isso nos conduz a outro nível da bibliodivesidade, ligado não só à diversidade de gênero mas também à diversidade atravessada pelas identidades de gênero(s).

\section{Desenho metodológico e análise de alguns casos na Argentina e no Brasil ${ }^{5}$}

Este trabalho propõe a aproximação de alguns casos de edição independente de obras sobre infâncias diversas a partir da exploração de tópicos como: identidades de gênero, famílias e infâncias trans. Trata-se de um estudo de casos que considera tanto as questões da publicação quanto as questões de gênero(s) e feminismos, em relação à cultura escrita, à história dos livros e à publicação.

Nosso roteiro pretende apresentar editoras independentes brasileiras e argentinas que abordam as questões LGBTQ+ e infâncias diversas; em seguida, brevemente, descrever e analisar os catálogos das editoras, sendo que nenhuma delas pertence a grandes grupos editoriais. Na última etapa, discutiremos e refletiremos sobre o tema, tentando delinear futuras abordagens de pesquisa.

\section{Editoras argentinas}

$\mathrm{Na}$ Argentina, no campo da literatura para crianças, Sardi (2015) sustenta que, historicamente, as mulheres aparecem associadas a identidades específicas (beleza, frivolidade, debilidade) e à sua submissão, tanto ao discurso masculino quanto ao discurso do mal. Nesse sentido, a autora diz que certas mulheres só são privilegiadas quando se encaixam num molde cultural, daí que "sujeitos sociais reais, donos de seu corpo e de sua sexualidade, com características diversas e múltiplas enquanto identidades e subjetividades existentes têm sido evitadas na literatura para crianças" (Sardi, 2015, p. 162).

As famílias, historicamente, também têm sido pensadas desde determinadas identidades heteroparentais, com mulheres e homens subsumidos a identidades reducionistas e cristalizadas. Larralde (2014) fez um estudo sobre mais de 60 títulos publicados no mundo, no período 20002012, para revelar a presença de pelo menos um personagem ou tópico que pode ser registrado no campo LGBTTTI. 6 A autora considera que as orientações sexuais e identidades de gênero são tratadas no campo da literatura para crianças, mas o trans é invisível, exceto para, na Argentina, os livros de duas editoras: Bajo el Arcoiris e Molinos de Viento. Outras casas que publicam livros sobre esses temas são: Niño Editor, Chirimbote e Muchas Nueces. ${ }^{7}$

Bajo el Arcoiris (Figura 1) é uma editora digital argentina cujos livros podem ser baixados gratuitamente. O catálogo é dedicado a contos infantis e juvenis e a relatos ilustrados sobre temas LGBTQ+, tais como o amor entre pessoas do mesmo sexo, o casamento igualitário, a

\footnotetext{
${ }^{5}$ Agradecemos a valiosa colaboração das pesquisadoras e professoras Fabíola Ribeiro Farias, Laura Erber e Amanda Ribeiro Barbosa, além do tradutor Sérgio Karam.

${ }^{6}$ A autora decidiu "não incluir a letra Q, referente a queer, no final da sigla, na medida em que, ao se referir a identidades de gênero/orientações sexuais e/ou identidades/modos de identificação política dos sujeitos envolvidos, acreditamos que isso seria contraditório com os princípios da teoria queer, cristalizando-a como uma identidade, fixando-a com uma letra nesse continuum" (Larralde, 2014, p. 18).

${ }^{7}$ Rolli e López Curyk sugerem que a editora independente, de escala média, Calibroscopio "editou dois títulos que foram pioneiros ao abordar questões de dissidência sexual na LIJ: La historia de Julia, la niña que tenía sombra de niño e Rey y Rey. Dessa forma, esses títulos de autores estrangeiros foram publicados pela primeira vez na Argentina, permitindo maior circulação" (2018, p. 83). O primeiro foi escrito por Christian Bruel e ilustrado por Anne Bozellec, em 1976, publicado na Espanha com trechos censurados em anos seguintes e, somente em 1997, foi republicado na França sem cortes. Há coedição da Calibroscopio (Argentina) com a Babel (Colômbia) em 2008 (republicada em 2016). O livro foi recomendado pelo blog "Feminacida: periodismo que ressurge" porque mostra os estereótipos de gênero nas crianças e a transexualidade. No Brasil, há uma edição pela Scipione (A história de Júlia e sua sombra de menino), de 2010. O segundo livro faz parte da coleção Libros de Arena. Foi escrito e ilustrado pelas holandesas Linda De Haan e Stern Nijland, em 2000, e publicado na Argentina em 2018.
} 
adoção homoparental e a identidade de gênero, segundo indica o blog da casa. Esse projeto editorial teve início em 2011, a partir do desejo da estudante Sofía Olguín, e tornou-se o primeiro projeto editorial dessa natureza na Argentina. Em várias entrevistas, Olguín menciona que a motivação para a criação deste selo era uma preocupação recorrente com a quantidade de notícias sobre suicídios de crianças e adolescentes gays, lésbicas ou trans.

A ideia é atingir todas as escolas, diz Olguín. Não escrevo esta literatura apenas para filhos de famílias homoparentais que crescem em um ambiente em que não existe tal discriminação. Escrevo para os filhos de famílias não-homoparentais, para que não cresçam com os preconceitos que todos crescemos (Olguín apud Heinrich, 2014, s.p.).

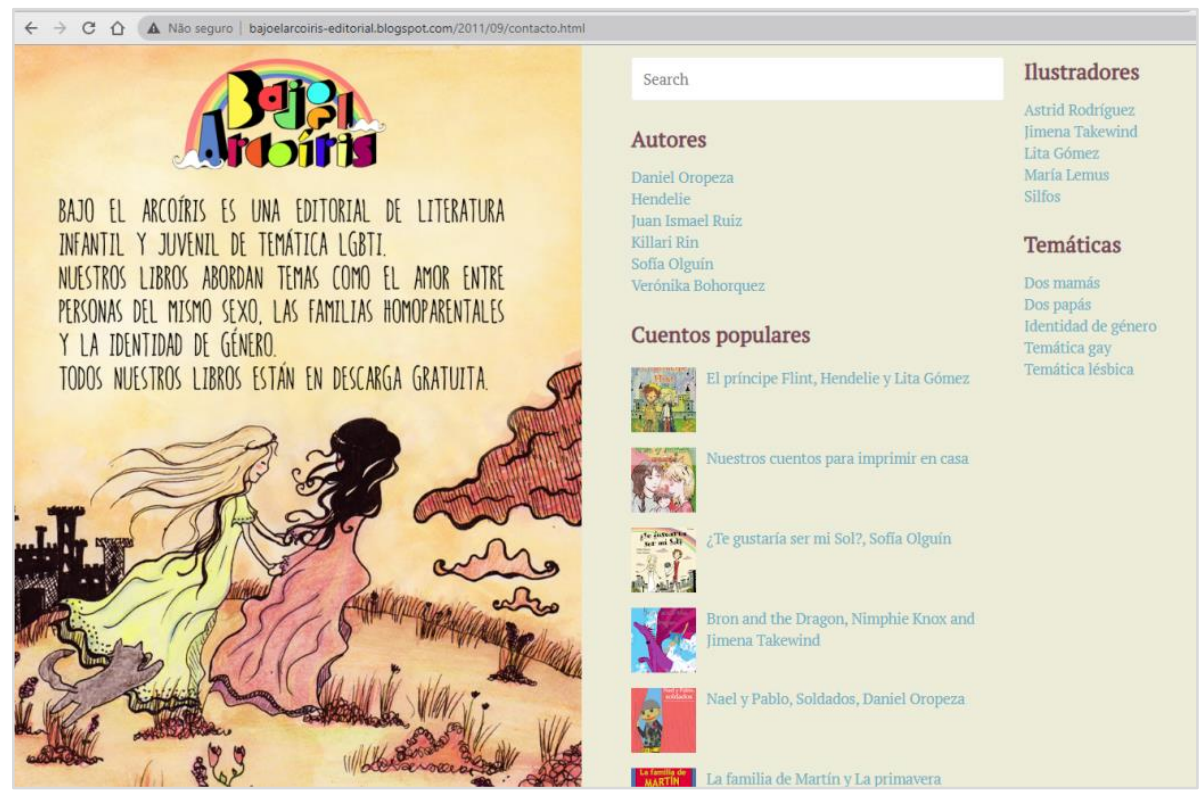

Figura 1 - Site da Bajo el Arcoíris Editorial

Fonte: http:/ / bajoelarcoiris-editorial.blogspot.com/

A editora Bajo el Arcoiris oferece títulos como La magia de una sonrisa, de Verónica Bohorquez e María Lemus; Mi conejo Mirlo, de Sofía Olguín e Silfos; Rosa y Julieta, mamás, de Daniel Oropeza e Silfos; e El príncipe Flint, uma história de amor em verso, também escrita por Olguín.

Molinos de Viento é outra iniciativa afim (Figura 2). O selo surgiu em 2012/2013 para reforçar a circulação de livros sobre esse novo repertório de tópicos que abrangem homoparentalidade, adoção, barriga de aluguel, bullying e diversidade sexual. São os primeiros três títulos da editora: ¿Cómo llegué a este mundo?, Hay muchas cosas que están bien (texto que é opcionalmente acompanhado por um livro de colorir) e Anita y sus dos mamás, todos de autoria de Darío Fernández. Vários desses títulos receberam o reconhecimento do Estado (nacional e da Cidade Autônoma de Buenos Aires) pela visibilidade que dão aos temas da inclusão e da não discriminação, bem como pelo tratamento de famílias diversas. A Molinos de Viento é uma das editoras que participam do estande "Várias infâncias", na Filba, assim como na Filfem e em outros eventos dedicados a livros e leitura. 


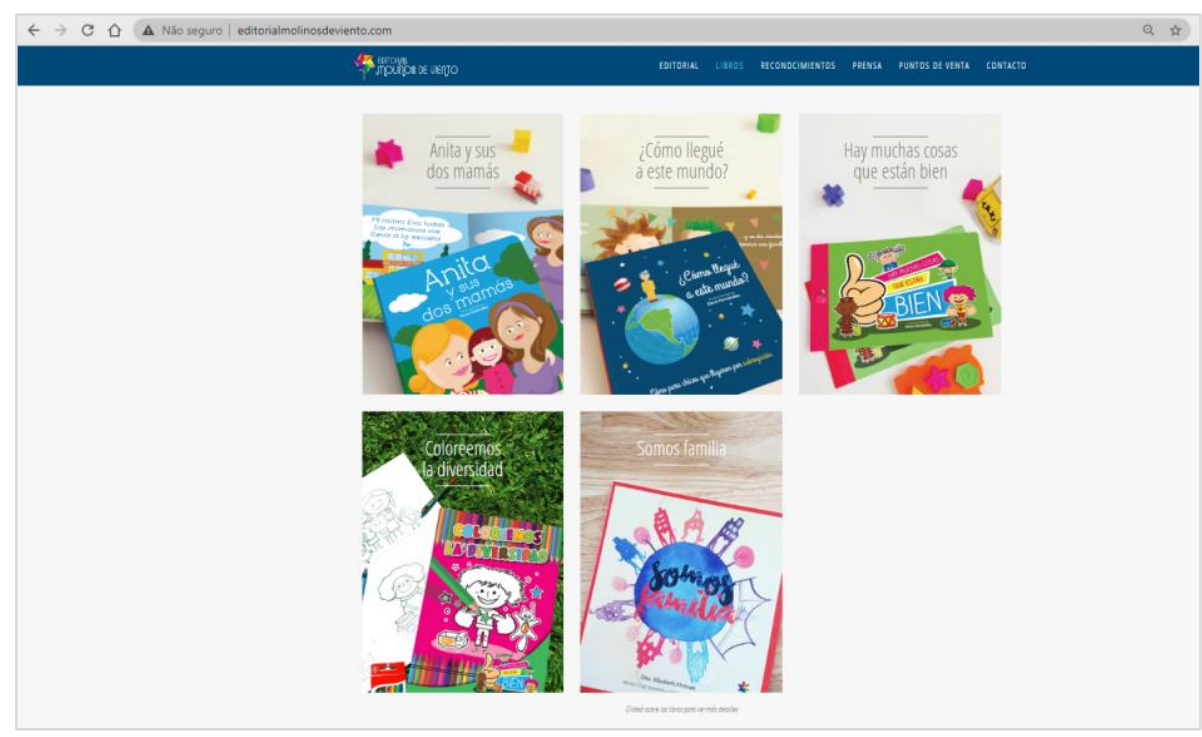

Figura 2 - Site da editora Molinos de Viento

Fonte: http:/ / www.editorialmolinosdeviento.com/

La Mariposa y la Iguana é uma das editoras mais representativas da Argentina, com forte marca feminista e, como apontam suas editoras Dafne Pidemunt e Leticia Hernando, as coleções do catálogo incluem ensaios, narrativas e poesia, atravessadas por questões de gênero e diversidade. Embora a casa tenha se originado com o objetivo de publicar autores contemporâneos, autores clássicos e ensaios foram adicionados ao longo do tempo, dando origem às coleções Palimpsestos e Praxis. No entanto, foram os \#Niunamenos, juntamente com a promulgação das leis sobre casamento igualitário e identidade sexual, que estabeleceram o caminho para "publicar questões de gênero, que enriqueceram a editora e lhe deram uma direção" (Szpilbarg, 2018, p. 10). De fato, seu catálogo apresenta uma seção sobre Diversidade, na qual também se publicam livros infantis. O título Una historia de amor muy espacial, de María Laura Sabino (Figura 3), tem ilustração muito sutil e centrada em uma família homoparental chefiada por duas mães, Lucrecia e Ana, confrontadas por uma bruxa que deseja separá-las.

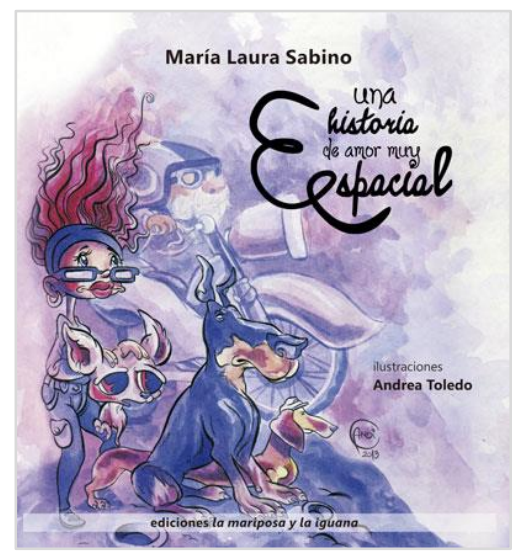

Figura 3 - Capa do livro das Ediciones La Mariposa y la Iguana

Fonte: https:/ /lamariposaylaiguana.com.ar/catalogo/

Chirimbote é uma casa de catálogo extenso e, como o define sua editora, Nadia Fink, "muito diversificado". Tem forte conteúdo feminista, sobre mulheres feministas, ativistas e lutadoras, 
na conquista de diferentes tipos de direitos. Por exemplo, o livro Micaela García "la Negra" para chicas y chicos é sobre Micaela, vítima de feminicídio. Além da principal coleção Antiprincesas, com 16 títulos, pela qual a editora ganhou notoriedade, o catálogo é organizado em torno de quatro eixos: Antiprincesas, Antihéroes, Educación en géneros e Infancias libres. Tal catálogo abrange vários pontos de vista, como a história de vida de mulheres feministas, ativistas, e não apenas a infância, alcançando também adultos dedicados à educação, ao acompanhamento de meninos e meninas, oferecendo temas ligados à diversidade sexual, de classes, raças e religiões. Em particular, a Chirimbote tem alguns títulos que abordam questões trans na infância e adolescência, como Pendeja: diario de una adolescente trans e Soy Alexa: infancias trans (figura 4).

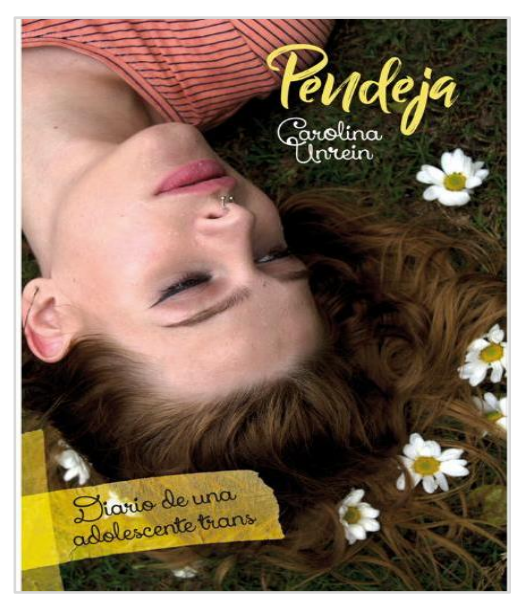

Figura 4 - Capa do livro Pendeja: diario de una adolescente trans

Fonte: https://tienda-chirimbote.mercadoshops.com.ar/pendejas

A editora Muchas Nueces foi criada em 2012 como cooperativa. Nos anos mais recentes, passou a publicar obras para "outras infâncias". É composta por dez membros de diferentes formações. Gonzalo Miranda conta que conheceu o parceiro Augusto Bianco durante seu curso universitário. Bianco era o fundador da editora Rompan Fila, que, durante a ditadura chilena, publicou diversos livros proibidos. Eles começaram a internalizar os temas e problemas da infância e, assim, decidiram se dedicar a um catálogo que tratasse as crianças como "sujeitos ativos". Por sujeitos ativos entendem aqueles/as capazes de lidar com situações muito complexas, como desemprego, prostituição ou infância trans. Nesse contexto, suas produções visam "proteger diversas infâncias" e aproveitar o contexto democrático para exigir a inclusão, por meio de suas obras. Como postulam na descrição do site:

Nós somos dedicados às crianças. Essa foi uma decisão deliberada, porque acreditamos que a ideia de "niñx" hoje é usada para espalhar apenas obras infantis que marcam a base retórica do mundo atual, para manter sua quietude, porque são os primeiros símbolos que as crianças internalizam e que são apropriados. Pelo contrário, queremos contribuir com produções sobre questões sociais, políticas, culturais e de identidade que nos atravessam como uma sociedade explicada a eles, porque os consideramos sujeitos de ação e construção. ${ }^{8}$

Dessa forma, o livro central e emblemático da editora, que teve muita circulação, é Crianzas: historias para crecer en toda la diversidad, de Susy Shock (Figura 5). Tal livro nasceu de emissões semanais transmitidas pela rádio pertencente à Cooperativa La Vaca. Mais tarde, foi compilado como livro. Trata-se de um conjunto de histórias que abordam infâncias que crescem na diversidade. São 28 episódios e dois prólogos (um da ativista trans Marlene Wayar e outro da editora Claudia Acuña), uma introdução da editora e um epílogo, que é uma carta de Susy a sua professora do ensino fundamental. Além disso, o livro traz ilustrações de Anahí Bazán Jara,

${ }^{8}$ Disponível em: http://muchas-nueces.com.ar/quienes-somos/. Acesso em: 19 mar. 2020. 
filha do autor. No prefácio, Marlene Wayar se pergunta quem pensa em crianças e afirma que aqueles que pensam nelas, em nossa sociedade, são as indústrias do consumo. No entanto, não existe uma indústria de cuidados e de acompanhamento de crianças e adolescentes trans.

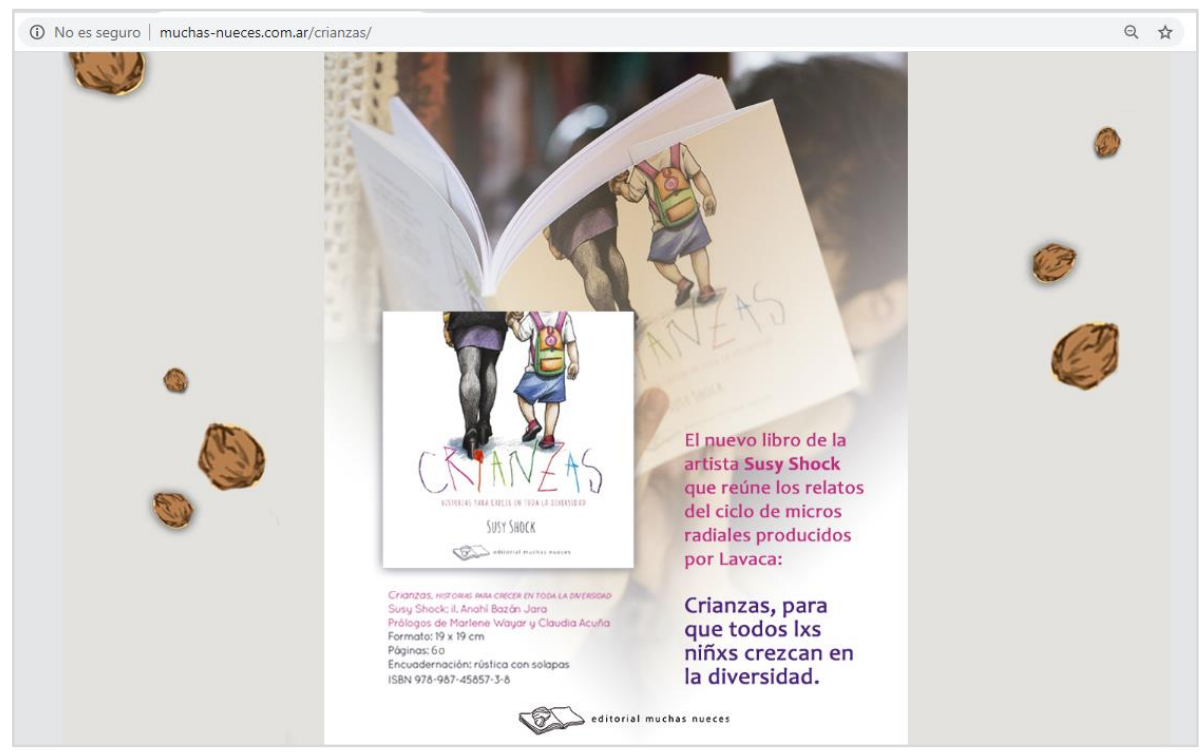

Figura 5 - Capa do livro Crianzas no site da editora Muchas Nueces

Fonte: http://muchas-nueces.com.ar/crianzas/

A editora Niño Editor foi criada em 2014 e, diferentemente das demais, emergiu "como produtora de conteúdo para a internet e seu primeiro projeto foi um aplicativo móvel chamado Love, uma adaptação animada e interativa de um livro de Gian Berto Vanni" (Jarast, 2019, p. 78-79). Com o tempo, a editora começou a publicar em papel e a se especializar em livros ilustrados, produzindo obras estrangeiras das décadas de 1940, 50 e 60, traduzidas pela primeira vez ao espanhol. A obtenção do Bologna Ragazzi Digital Award, em 2014, entre outros reconhecimentos (na Suíça e no Japão), fixaram-na no mapa das editoras independentes que publicam livros de literatura infantil e juvenil. A Niño Editor participa de diferentes feiras de livros, como a Independent Publishers Fair (FED), a Book Fever (evento organizado pela Biblioteca Nacional argentina) e, em 2019, teve estande próprio na Filba. De acordo com Jarast (2019), é uma pequena editora composta por três proprietários e editores, responsáveis pela divulgação do catálogo nas redes. Uma das estratégias editoriais, nesse sentido, é não apenas pautar a mídia, mas movimentar os livros de temas de provável interesse temático, como Barbie $\mathcal{E}$ Milo, que trata de questões de gênero (Figura 6).

Rolli e López Curyk (2018) mostram que no livro Barbie \& Milo, uma história de amor (2016), das autoras norueguesas Kari Tinnen e Mari Kanstad Johnsen, o protagonista desafia tanto as expectativas de seu pai quanto os padrões sociais, ao desejar uma boneca, considerada um brinquedo para meninas. Diego Trerotola (2018) afirma que o livro não trata de nenhuma orientação sexual ou identidade de gênero em particular, baseando-se no fato de que, como o título original indica (Nils-Barbie \& Pistol-Problemet), aborda uma questão com armas, deslocando o conflito da história da criança para focar o pai. Tal deslocamento seria "uma das originalidades do livro, sua estratégia literal de desarmar o patriarcado, e é uma pena que não tenha sido traduzido para o espanhol, a única crítica que pode ser feita à excelente edição local" (Trerotola, 2018, s.p., tradução nossa). 


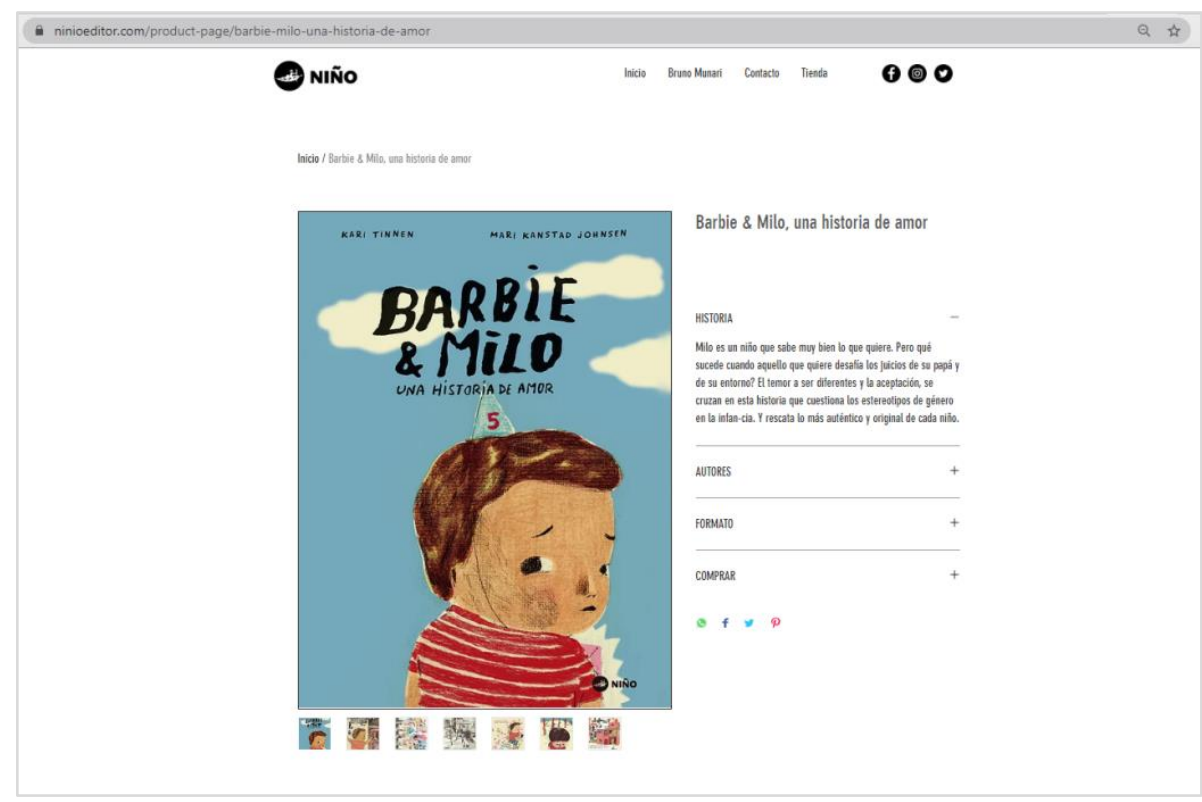

Figura 6 - Site da Niño Editor e capa do livro Barbie $\mathcal{E}$ Milo

Fonte: https://www.ninioeditor.com/product-page/barbie-milo-una-historia-de-amor

\section{Editoras brasileiras}

No Brasil, ainda não encontramos editoras exclusivamente dedicadas aos livros para crianças sobre identidades de gênero e infâncias trans. ${ }^{9}$ No cenário existente, editoras independentes publicam obras sobre o tema, às vezes em coleções dedicadas às crianças, às vezes esparsamente, sem, no entanto, abrirem mão de seu catálogo mais geral. Talvez tal situação se deva às dificuldades de base que se impõem num contexto de conservadorismo crescente, mas muito provavelmente isso não chegaria a impedir o nascimento e a existência de algum selo especializado, com coragem para abordar/atacar assuntos ligados às identidades diversas.

Um episódio de tentativa de censura ocorrido durante a Bienal do Rio de Janeiro em 2019, como já mencionamos, terminou por dar voz a diversas editoras pequenas, ameaçadas como seus autores e livros. A Editora Rico talvez tenha sido a que mais se destacou, uma vez que havia publicado livros de temática gay. Fundada em 2017, é uma das frentes de ação da Rico Produções, do Rio de Janeiro, que publica livros, quadrinhos e oferece cursos, além de desenvolver projetos de incentivo à leitura (Figura 7). A editora se divide em quatro selos, que podem ser considerados coleções: Riquezas, Apimentando, Carnavalize e Se liga. O catálogo apresenta livros de literatura erótica e, segundo o site, o selo Se Liga seria o responsável pela publicação de livros "para todos os pilares da diversidade: sexual, étnica, de gênero, de pessoas com deficiência etc., além de obras com viés feminista", mas não especialmente para crianças. Para a juventude, sob o rótulo de "chick lit", foram publicados títulos como Conto de fada às avessas, de Jariane Ribeiro, e outros ainda chamados de "jovem adulto". A literatura LGBTQ+, segundo declara a editora, ficou a cargo de obras como Coração de unicórnio, poemas de Diego Wayne, e As luzes de mim, romance, de Roberto Azevedo. Merece destaque o título Cor não tem gênero, de vários autores, uma coletânea de contos que, segundo o site da editora, é um "manifesto pela diversidade".

\footnotetext{
${ }^{9}$ Pouco depois da produção deste artigo, a pesquisadora Amanda Ribeiro Barbosa nos presenteou com o site da editora Caqui, de Curitiba, PR. O endereço é https://www.editoracaqui.com.br/ e na aba "Quem Somos" é possível conhecer os contornos do projeto editorial da casa, fundada e dirigida, também em anos recentes, essencialmente por mulheres: "a Editora Caqui é um negócio social. Nossa missão é publicar livros e produzir recursos educativos com temáticas de educação sexual, feminismos, masculinidades positivas e alternativas, igualdade de gênero, educação não-machista, antirracismo e prevenção contra as violências sexuais. Acreditamos que a informação de qualidade relacionada a esses assuntos é um direito de todas as pessoas, desde a primeira infầncia".
} 


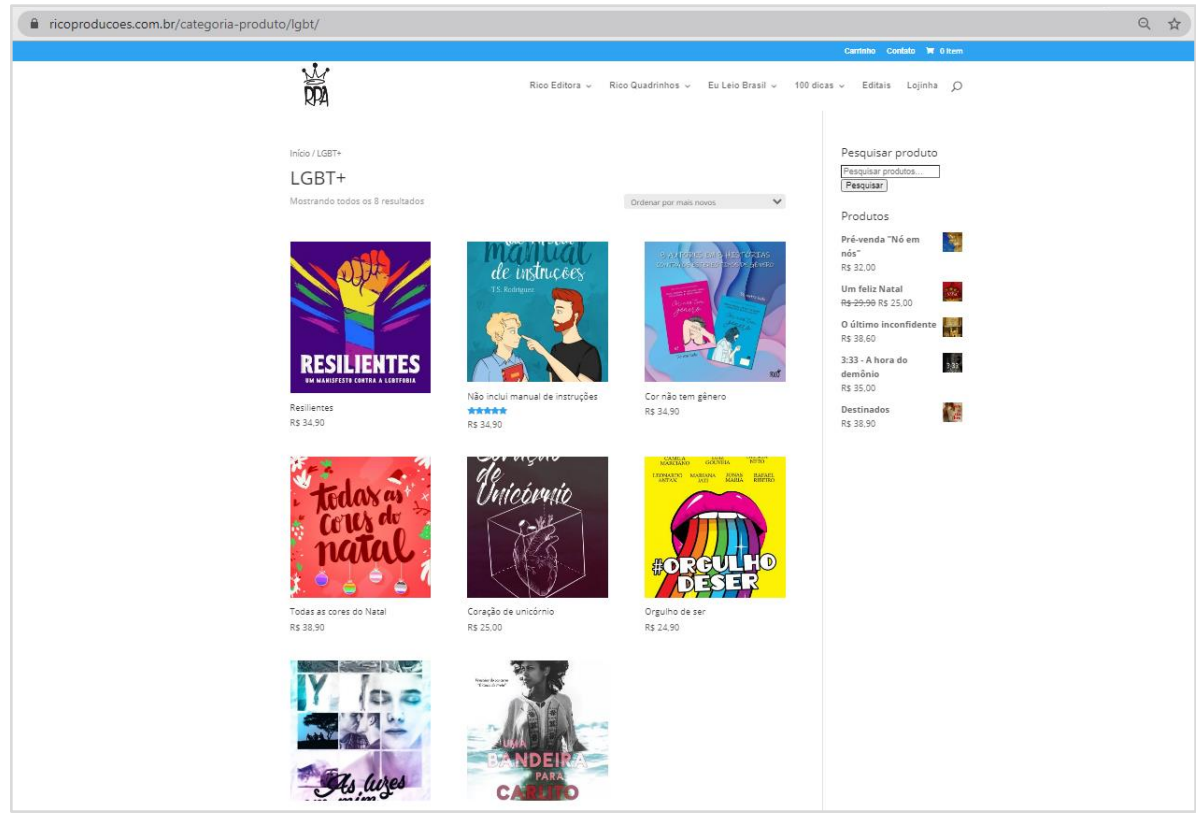

Figura 7 - Site da editora Rico

Fonte: https:/ / ricoproducoes.com.br/categoria-produto/lgbt/

A Javali é uma editora de Belo Horizonte, fundada em 2015 com a finalidade de publicar dramaturgia. Embora não seja uma casa dedicada aos livros para crianças, publicou em 2019 um título, Por quê? Teatro para infâncias e juventudes, organizado por Assis Benevenuto e Vinícius Souza (Figura 8), que compila peças de teatro dirigidas ao público infantil, entre as quais está Meninonina, de Sérgio Abritta, que trata diretamente da temática trans/identidade de gênero, conforme sinopse: "Uma família como qualquer uma. Um garoto como qualquer outro. E a história de uma menina que não queria ser menino". Diz o site da editora:

É possível pensar a infância e a juventude do nosso tempo a partir do teatro? Quais caminhos podemos criar para dialogar com e acerca das crianças e dos adolescentes que habitam a vida contemporânea? A escrita cênica seria uma via para refletir, questionar e até propor outras possibilidades em relação aos dilemas vividos neste início de século? Como reinventar a existência (e seguir resistindo), por meio de experiências que mesclam ficção e realidade, invenção e discursividade, diante de um contexto histórico-políticosocial que tem aniquilado práticas artísticas e negligenciado suas potências para a vida compartilhada? (pelo prefaciador Charles Valadares)

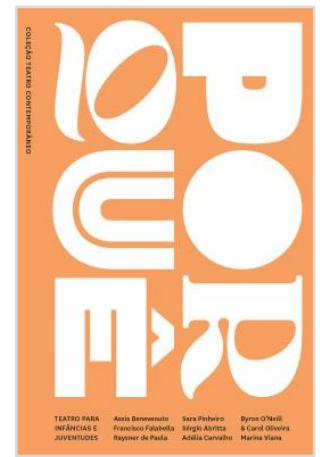

Figura 8 - Capa do livro Por quê?

Fonte: https://www.editorajavali.com/product-page/por-quê 
Já a editora Livros da Matriz foi fundada em 2012, em São Paulo, com o objetivo de publicar livros para crianças, participando de seu "percurso leitor desde o início". Segundo declaram, fazem uma "seleção criteriosa de títulos, editados com cuidado, tratando de temas atemporais". O catálogo atual tem títulos sobre inclusão, consumismo, medo, diferença e gênero, sendo este último tema nosso foco neste trabalho. Das obras já publicadas pela Livros da Matriz, O menino perfeito é o destaque (Figura 9). Trata-se de um livro-álbum de autoria do espanhol Bernat Cormand, com tradução de Dani Gutfreund ao português. Em sua editora original, foi considerado um livro "perturbador" e posicionado no catálogo de adultos, mas, no Brasil, é parte de um catálogo francamente dirigido a crianças.

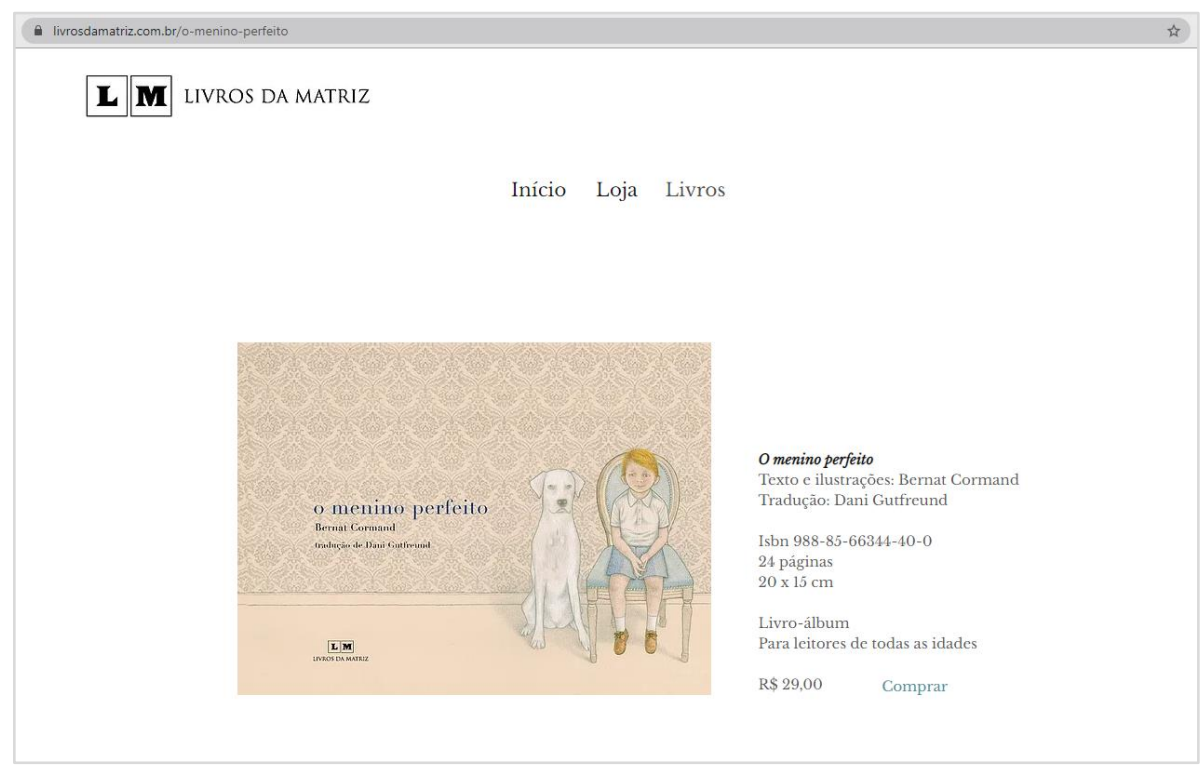

Figura 9 - Site da editora Livros da Matriz

Fonte: https:/ / www.livrosdamatriz.com.br/o-menino-perfeito

A Dagoia Livros (Figura 10) iniciou suas atividades de edição em 2017, no Rio de Janeiro, produzindo livros "com projetos gráficos diferenciados" e "liberdade de design", a fim de que seus/suas leitores/as tenham "experiências inusitadas". Em seu site, a editora se autodeclara "independente e criativa". Foi criada e é dirigida pela designer Tatiana Rivoire (projetos e ilustrações) e conta com a contribuição da jornalista Anna Luiza Guimarães na edição dos textos. A Dagoia expõe sua produção em feiras independentes por todo o Brasil. Por enquanto, conta com catálogo pequeno, mas dedicado aos livros para crianças, sendo metade deles sobre questões de gênero, a exemplo de Sapa Tônia (da própria Tati Rivoire) e Trans Eudora Trans (Tati Rivoire e Luiz Prata). Nota-se na Dagoia Livros forte característica de autopublicação, elemento afinal comum à fundação de muitas editoras independentes. 


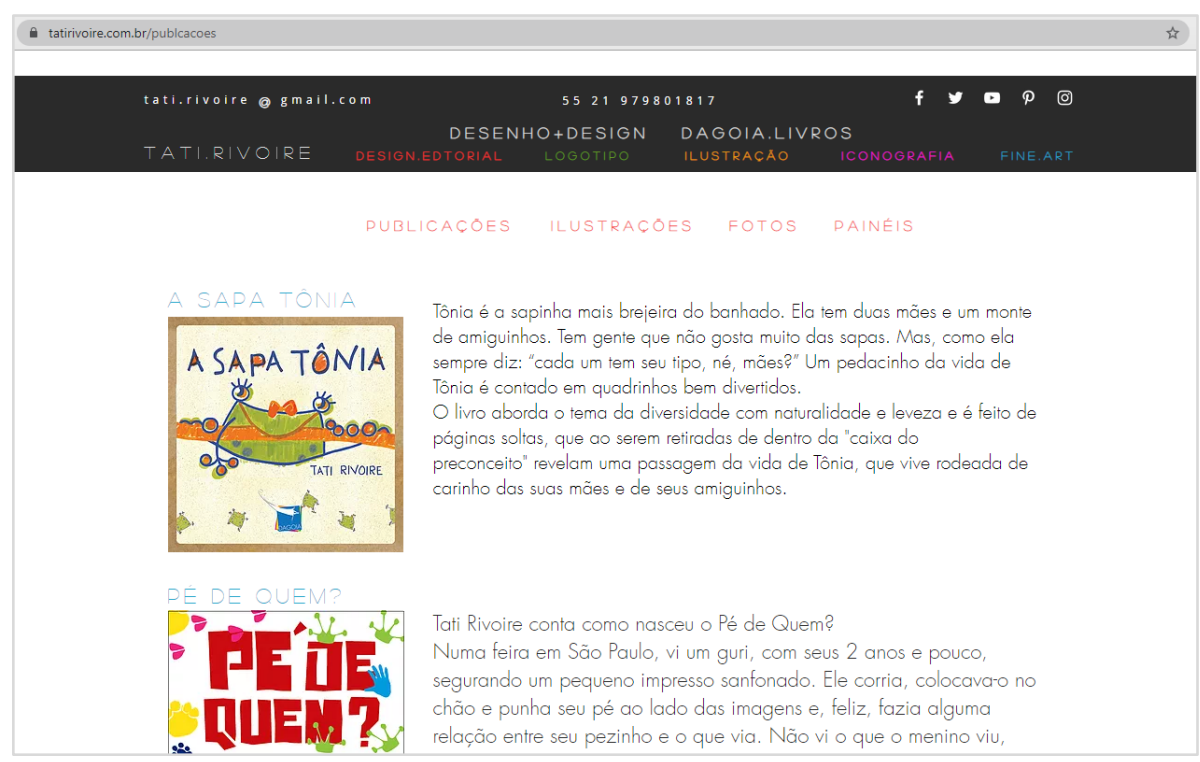

Figura 10 - Site da Dagoia Livros e capa da obra Sapa Tônia.

Fonte: https://www.tatirivoire.com.br/dagoia

Das editoras brasileiras que publicam obras para crianças e abordam temas LGBTQ+ e identidades de gênero, a Boitempo Editorial talvez seja um caso à parte (Figura 11). Trata-se de uma editora de mais de três décadas de atuação, com declarada coloração ideológica de esquerda, que construiu sua respeitada reputação, ao longo dos anos, por meio da composição de um catálogo cuidadoso e coerente com seus propósitos. (Re)fundada por Ivana Jinkings, em São Paulo, embora tenha começado pequena, tornou-se uma das mais consolidadas editoras do Brasil (Ribeiro, 2019). Ainda hoje, é de capital nacional, sustenta-se na publicação de um catálogo bem cuidado e se mantém ativa no debate sobre políticas do livro e independência editorial. É uma das editoras afiliadas à Libre (Liga Brasileira de Editoras), estando presente em feiras como a Primavera do Livro, desde o começo, nos anos 2003 e 2004.

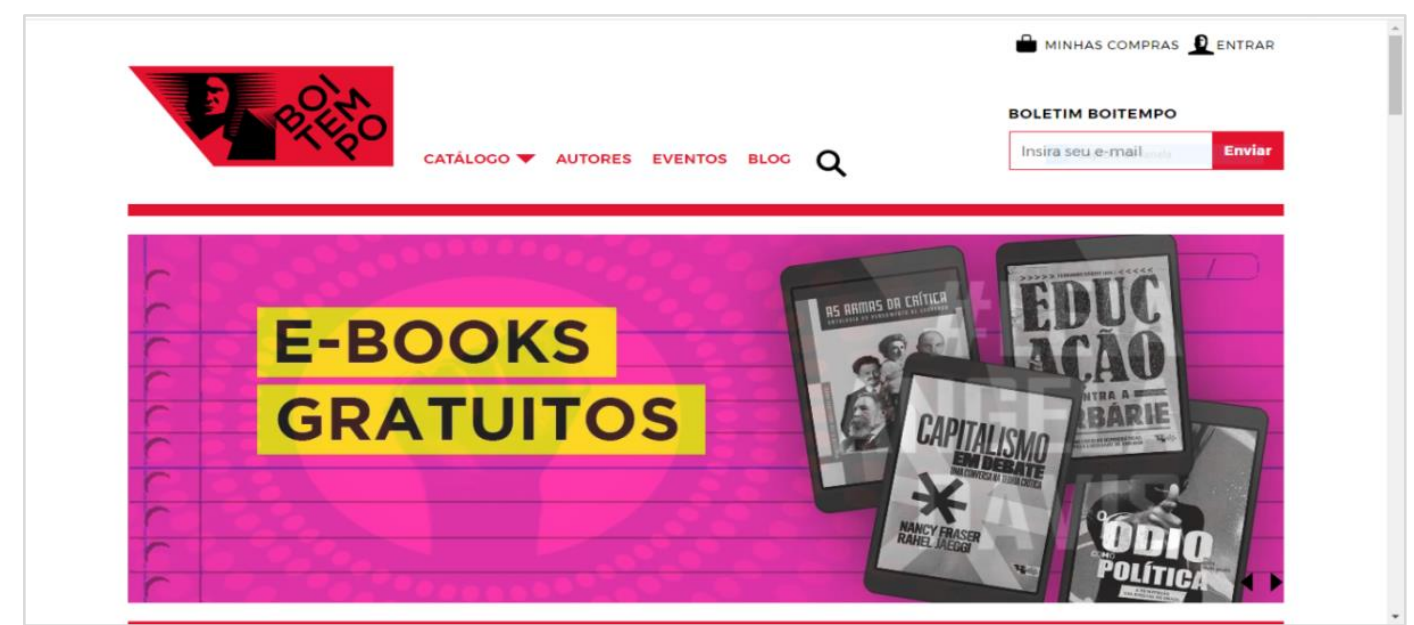

Figura 11 - Site da Boitempo Editorial onde se encontram os livros da coleção Boitatá.

Fonte: https://www.boitempoeditorial.com.br/

Embora, na origem, não seja uma editora de livros para crianças, desde 2015 vem publicando para esse público, por meio de uma coleção intitulada Boitatá, sendo seus primeiros títulos produzidos com a finalidade de explicar teorias socialistas às crianças. Para o caso deste 
trabalho, destacamos obras como As mulheres e os homens, de Equipo Plantel (ilustrado por Lucí Gutiérrez e traduzido ao português por Thaisa Burani) e Pode pegar! (de Janaina Tokitaka), diretamente ligadas ao debate sobre identidade de gênero. Tangencialmente ao tema, a coleção Boitatá ainda publica outros livros, incluindo obras para crianças de autoria de Bell Hooks, uma das mais conhecidas escritoras feministas negras em circulação no Brasil.

\section{Considerações finais}

$\mathrm{Na}$ pesquisa realizada para este artigo, encontramos várias editoras independentes que buscam, por meio de diferentes formatos - contos, livros-álbum, livros para colorir, livros ilustrados, etc. - repensar as identidades de gênero e, em particular, a constituição das famílias e das infâncias diversas, como mostram os casos na Argentina e no Brasil. Segundo Larralde (2014), vivemos hoje certo paradoxo porque as leis ainda não avançaram o suficiente; e mesmo quando elas avançam devido a mudanças e a direitos sociais, a edição para crianças ainda não segue na mesma velocidade:

[...] vemos que - de 2001 em diante - há cada vez mais textos com protagonistas gays ou lésbicas e histórias com pais solteiros, mas não encontramos mais casos de transexualidade, transgênero, intersexo ou travestis em nosso corpus, bem como outros tipos de arranjos familiares. Por outro lado, vale a pena nos perguntar como seria um travesti - no nível das ilustrações - em uma história infantil (Larralde, 2014, p. 91, tradução nossa).

Certamente, de 2014 até agora, há casos que levam em consideração uma visão mais ampla da infância. Embora o Brasil e a Argentina sigam em ritmos e intensidades distintos, é possível verificar uma história como a de Luana, criança trans, a primeira criança que foi reconhecida pelo Estado argentino e que pôde trocar seu gênero. A partir daí, é importante observar mudanças e diferenças no setor editorial, em especial na edição independente.

As editoras independentes, como afirma Szpilbarg (2021), muitas vezes são as primeiras a assumir o risco ou a aposta de publicar sobre determinados temas. Com relação a isso, as editoras independentes 'diversas' são as que, há anos, se dedicam a produzir e a publicar textos feministas, dissidentes e que refletem sobre problemáticas comuns de populações e comunidades discriminadas, enriquecendo o que poderia ser a bibliodiversidade genérica, em termos de identidades sexuais, gerando práticas editoriais performativas e, por outro lado, planos de ação que se relacionam também com os processos de concentração do setor editorial. Dessa forma, após este trabalho, podemos pensar numa hipótese segundo a qual os catálogos estudados expressam "uma tendência contemporânea dos campos editoriais: editores independentes, pequenos ou autogerenciados estão ligados à vanguarda; e suas publicações ocorrem no momento em que os fenômenos sociais e políticos estão 'vivos' como reivindicações na sociedade, enquanto os editores de grande escala, em muitos casos, aderem ao fenômeno editorial quando ele já está instalado e em grande escala", entendendo-o ou considerando-o como uma ação de mercado (Szpilbarg, 2021, p. 240, tradução nossa).

Uma das formas como editores comerciais ou de grande escala contribuem para esse fenômeno editorial é por meio da tradução de livros clássicos sobre infâncias diversas, desde que sejam obras já "bem-sucedidas" em outros países. Assim, mesmo quando publicam sobre diversidades, não levam em consideração os contextos locais em que tais infâncias ocorrem. Ao que parece, uma abordagem de infâncias e famílias diversas, identidades de gênero e orientações sexuais, entre outros tópicos, nos contextos argentino e brasileiro, ocorre mais no campo da edição independente. Outro modo de editores comerciais e de grande escala abordarem o assunto é publicar autores ou títulos editados primeiro por editores independentes. Trata-se de algo recorrente nos livros sobre feminismos e que parece ser uma tendência em relação à literatura para crianças.

Enfim, falar em bibliodiversidade - termo associado, desde o início, à produção independente -, hoje, deve considerar e incluir, em conceituações e definições contemporâneas, questões de diversidade sexual e de gênero. Nosso trabalho buscou refletir sobre os significados contemporâneos do termo "bibliodiversidade", em particular, por meio do exemplo de editores independentes que têm praticado tal expansão conceitual na Argentina e no Brasil. 


\section{Referências}

BAYARDO, Rubens (2008). Gestión cultural, economía de la cultura y políticas culturales ante la diversidad cultural. In: BOBBIO, Daniela (Comp.). Tensiones: Selección de conferencias del Programa de Formación en Gestión Cultural. Córdoba: Centro Cultural España. p. 42-71.

BITTNER, Robert (2019). Digging in to the alphabet soup: exploring trends and embracing change in LGBTQ+ YA Literature. Jeunesse: Young People, Texts, Cultures, v. 1, n. 11, p. 179-183. Disponível em: https://bit.ly/30PyzPl. Acesso em: 10 mar. 2020.

BUSTAMANTE FAJARDO, Mauricio; SYMMES COLL, Constanza Aída (2013). Los editores independientes y la constitución de un capital simbólico transnacional: condiciones sociales del ingreso de la diversidad cultural en Chile. Revista Del Museo De Antropología, v. 1, n. 6, p. 91-106. Disponível em: http:// bit.ly/3tp4dzt. Acesso em: 10 mar. 2020.

COLLEU, Gilles (2008). La edición independiente como herramienta protagónica de la bibliodiversidad. Buenos Aires: La Marca Editora.

CORMAND, Bernat (2017). Histórias sem armários. Emília, 18 out. Disponível em: https://revistaemilia.com.br/historias-sem-armarios/. Acesso em: 2 abr. 2020.

DEANGELI, Melina (2018). Práctica política y diversidad sexual: ciudadanía y derechos en las demandas del activismo LGTBIQ en Argentina. Oxímora. Revista internacional de ética y política, n. 13, p. 360-372 jul./dez. Disponível em https://doi.org/10.1344/oxi.2018.i13.22116. Acesso em: 13 abr. 2020.

GALLIAND, Étienne (2019). Les interventions publiques dans le secteur du livre. Objectifs, formes, niveaux de développement et principales caractéristiques. Bibliodiversity: les mutations du livre et de l'édition, Dossier Les politiques publiques du livre, p. 4-17.

HEINRICH, Milena (2014). La literatura infantil se hace eco de la diversidad sexual y los nuevos paradigmas familiares, Telam, 9 dez. Disponível em: http:/ / bit.ly/2N9LNCU. Acesso em: 31 mar. 2020.

JARAST, Nathalie (2019). Comunicación de las Editoriales de Literatura Infantil y Juvenil en Argentina en el siglo XXI: estudio de dos casos Norma Argentina y Niño Editor. Dissertação (Mestrado em Gestión de Contenidos) - Universidad Austral, Buenos Aires.

JENKINS, Christine A.; CART, Michael (2018). Representing the rainbow in young adult literature: LGBTQ+ Content since 1969. Maryland: Rowman \& Littlefield.

LARRALDE, Gabriela (2014). Los mundos posibles: un estudio sobre la literatura LGBTTTI para niñxs. Ciudad Autónoma de Buenos Aires: Título.

MIHAL, Ivana (2013). Actores y procesos en la gestión de la Bibliodiversidad. Revista Alteridades, n. 45, p. 123-136. Disponível em: http:/ / bit.ly/3qTUxLy. Acesso em: 12 mar. 2020.

MIHAL, Ivana (2019). Políticas editoriales universitarias y apuestas a catálogos con perspectiva de género(s). Revista Telar, n. 23, p. 117-136. Disponível em: http:/ / bit.ly/2Z1DGLj. Acesso em: 12 mar. 2020.

NÖEL, Sophie (2018 [2012]). La edición independiente crítica: compromisos políticos e intelectuales. Villa María: Eduvim.

PERRIAM, Christopher (2012). Una lectura culta, amena y didáctica: lo "middlebrow queer" y la construcción de identidades en la narrativa popular gay española 1999-2009. De Signis, n. 19, p. 79-87. Dossier Estudios queer: semióticas y políticas de la sexualidad.

RIBEIRO, Ana Elisa (2019). Boitempo Editorial e Ivana Jinkings: um quarto de século de uma editora de esquerda no Brasil. Pontos de Interrogação, v. 9, n. 1, p. 201-226. Disponível em: https://bit.ly/3rBZIjX. Acesso em: 19 mar. 2020.

RIBEIRO, Ana Elisa (2020). Tem prescrição que é cega. Revista Pessoa, 9 mar. Disponível em: http:// bit.ly/3vte21f. Acesso em: 2 abr. 2020.

ROLLI, Florencia; LÓPEZ CURYK, Diego (2018). Contrabando de plumas. Sexualidades disidentes y literatura infantil. Catalejos, v. 4, n. 7, p. 75- 96, dic. 
SARDI, Valeria (2015). Lecturas en conflicto: miradas sexo/genéricas en torno a un corpus de textos de María Teresa Andruetto. Catalejos. Revista sobre Lectura, Formación de Lectores y Literatura para Niños, v. 1, n. 1, p. 159-176, dic. Disponível em: http:/ / bit.ly/3c9479g. Acesso em: 17 mar. 2021.

SZPILBARG, Daniela (2018). Armas cargadas de futuro: hacia una historia feminista de la edición en Argentina. Malisia, n. 5, p. 15-29, ago. Dossier "Mujeres y Edición”.

SZPILBARG, Daniela (2019). Cartografía argentina de la edición mundializada: modos de hacer y pensar el libro en el siglo XXI. Temperley: Tren en Movimiento.

SZPILBARG, Daniela (2021). El fin del príncipe azul: catálogos feministas para infancias diversas. El caso de la Colección Antiprincesas (Argentina). Cuadernos del Centro de Estudios en Diseño y Comunicación, ano 24, n. 124, p. 227-243, jan.

TREROTOLA, Diego (2018). Abrir el juego. Página 12, Soy, Buenos Aires, 17 ago. Disponível em: http:/ / bit.ly/3rViVhi. Acesso em: 19 mar. 2020.

\section{Nota}

Ivana Mihal e Daniela Szpilbarg são pesquisadoras do Consejo Nacional de Investigaciones Científicas y Técnicas (Conicet) e este artigo é parte de seu trabalho de pesquisa. No Brasil, ele se insere no âmbito de um projeto sobre editoras mineiras e brasileiras financiado pela Fundação de Amparo à Pesquisa do Estado de Minas Gerais - Fapemig (APQ-0002128). 